\title{
As condições do trabalho docente na educação infantil no Brasil: alguns resultados de pesquisa (2002-2012)
}

Childhood teacher working conditions in Brazil: some research findings (2002-2012)

\author{
Lívia Fraga Vieira \\ Tiago Grama Oliveira \\ Universidade Federal de Minas Gerais
}

\section{Resumo}

A partir de um levantamento bibliográfico inicial, que compreende o período entre 2002 e 2012 , de artigos em periódicos disponibilizados pela base SciELO Brasil, de trabalhos apresentados nas reuniões anuais da ANPEd e de dissertações/teses cujos resumos constam no Banco de Teses da Capes, produzimos um quadro com os principais fatores que constituem as circunstâncias condicionantes do trabalho docente em creches e pré-escolas brasileiras. Os resultados, obtidos a partir de descritores como "trabalho", "educação" e "infantil", foram classificados segundo os principais aspectos relacionados às condições de trabalho conforme a literatura na área: identidade/aspectos subjetivos, políticas públicas educacionais, condições profissionais e saúde/bem-estar. Constatamos que a realidade profissional das/os trabalhadoras/es da educação infantil no Brasil é marcada pela atribuição de obrigações que não possuem respaldo nas condições de realização fornecidas pelo poder público. Situações de estresse, mal-estar, adoecimento e insatisfação laboral foram frequentemente relatadas nos estudos.

Palavras-chave: Condições do trabalho docente. Educação infantil. Revisão bibliográfica.

\section{Abstract}

Based on a preliminary review of literature (period 2002-2012) of articles available in the SciElo Brazil (database), papers presented at ANPEd (National Association of Research and Graduate in Education), and thesis/dissertations whose abstracts are in the Capes Database, we delineate a frame with the main factors that influence teacher working conditions in day-cares and pre-schools in Brazil. The findings, obtained with descriptors such as "work", "education" and "childhood", were classified according to the main aspects in the literature review related to work conditions: identity/subjective aspects, educational policies, employement conditions and health/welfare. We found that the professional reality of the workers in Childhood education in Brasil is marked by the assignment of obligations that have no support in their fulfillment conditions provided by the government. Stress situations, burn out, illness, and labor dissatisfaction were frequently reported in the studies investigated.

Keywords: Teacher working conditions. Childhood education. Review of literature. 
Quando perguntamos "em que condições trabalham os sujeitos docentes da educação infantil no Brasil", vêm-nos à mente as impressões que temos da realidade circunscrita que conhecemos. Como grande parte das instituições de educação infantil públicas está sob a responsabilidade das secretarias de educação municipais, não se pode homogeneizar ou generalizar a partir dos lugares e situações que já tivemos contato, seja pessoalmente ou por estudos de casos isolados.

Visto que no Brasil temos poucos estudos nacionais sobre a educação infantil que tratam do caráter profissional do trabalho docente, envolvendo pesquisas que passam pelas características empregatícias e chegam ao impacto das contradições da profissão sobre a subjetividade dos sujeitos docentes, um caminho é descobrir e problematizar as pesquisas que, mesmo de abrangência mais restrita, vêm sendo feitas e publicadas em artigos, dissertações e teses.

Este trabalho tem o objetivo de apresentar os resultados de levantamento da literatura publicada sobre condições de trabalho docente na educação infantil no Brasil, no período de 2002 a 2012, na forma de teses, dissertações, artigos em periódicos e em anais das Reuniões Anuais da Associação Nacional de Pós-Graduação e Pesquisa em Educação - ANPEd.

Inicialmente apresentamos a conceituação de "condições de trabatho" e algumas informações sobre o perfil dos professores da educação infantil no Brasil, com base nas informações do Censo Escolar-2012 do MEC/Inep (conferi no site do MEC). Descrevemos a metodologia de seleção dos textos e em seguida os apresentamos, destacando alguns temas, convergindo para as considerações finais.

\section{Condições de trabalho docente: breve conceituação}

Oliveira e Assunção (2010) sintetizam um conceito de condições de trabalho docente que compreende o contexto sócio-histórico no qual se situam as relações de trabalho. Considera-se, nos sistemas escolares, a estrutura física das unidades educacionais, as normas que organizam a dinâmica das interações na instituição, os recursos materiais disponíveis para a realização das atividades, as condições de emprego - cargo, função, vínculo de contratação, carga horária de trabalho, remuneração, plano de carreira, formação continuada, como também a experiência relacional entre os sujeitos docentes 
e com os sujeitos discentes - e as percepções e os efeitos objetivos e subjetivos de todo esse conjunto de fatores e processos.

trabalho docente, além de não se restringir às relações de ensino/ aprendizagem que acontecem na classe, não diz respeito exclusivamente ao cargo de professor, ou seja, inclui diversas "[...] funções, tarefas, especificidades e responsabilidades" e compõe a profissionalidade de "educadores, monitores, estagiários, diretores, coordenadores, supervisores, orientadores, atendentes, auxiliares, dentre outros." (OLIVEIRA, 2010, p. 1). Em especial, no caso da educação infantil, o envolvimento de todas/os nas experiências de transformação educativa das crianças constitui a maior parte do labor que vivenciam.

Sobre as condições psicossociais do trabalho docente, Chávez e Garrido (2010) dão destaque à organização dos processos de trabalho e às relações laborais e de poder. Temos, então, as ambiguidades e contradições entre a realidade e a prescrição e entre as regras e as ações, o apoio especializado, a autonomia sobre as atitudes e atividades, a consistência e o alcance dos sentidos do trabalho, o clima laboral, as possibilidades da prática docente reflexiva, a participação escolar e as relações entre a unidade educacional e o entorno social.

Nesse sentido, as condições de trabalho na educação compreendem tudo aquilo que é necessário para os sujeitos docentes desempenharem com sucesso e bem-estar o trabalho que thes cabe. Se o que é proposto consiste no oferecimento de condições para que as crianças possam brincar, aprender e produzir conhecimento, descobrir, reflexivamente, através das interações com o meio ambiente e com outros sujeitos e compreender, criar e atribuir sentidos e significados àquilo que percebem e àquilo que fazem, é preciso que uma série de circunstancialidades favoráveis seja realidade.

\section{Perfil das professoras de educação infantil no Brasil}

Os/as professores/as dessa etapa constituem $21 \%$ dos docentes da educação básica no Brasil. Segundo o Censo Escolar de 2012 do MEC/Inep, eles compõem um universo informado de 443.405 docentes, majoritariamente mulheres (97\%). Quase 70\% são servidores das redes municipais de ensino; mais da metade (64\%) possui formação em nível de ensino superior, sendo que, 
destes, 90\% possuem licenciatura em educação/pedagogia; apenas 16\% nas creches e 18\% nas pré-escolas frequentaram algum curso/atividade de formação continuada com duração de, no mínimo, 80 horas, no último ano; quase todos/as exercem suas funções em apenas um estabelecimento de ensino.

Outras informações, levantadas em 2009 pela pesquisa "Trabalho Docente na Educação Básica no Brasil" IOLIVEIRA; VIEIRA, 2010; VIEIRA; OLIVEIRA; OLIVEIRA; VICTORINO, 20131, revelaram que 37\% das respondentes da educação infantil, de um total de 1838 sujeitos docentes de creches/pré-escolas públicas e conveniadas, são principal provedor de renda na família, $69 \%$ têm filhos e $52 \%$ são casadas. Em relação ao vínculo trabalhista, apurou-se que $57 \%$ são estatutárias; $20 \%$ são temporárias/substitutas/designadas e 12,4\% estão no regime de contrato pela CLT - Consolidação das Leis do Trabalho.

\section{Metodologia da pesquisa}

As fontes de pesquisa foram: a base SciELO Brasil (Scientific Electronic 134 Library Online Brasil), o portal da ANPEd (Associação Nacional de PósGraduação e Pesquisa em Educação) e o Banco de Teses da Capes/MEC |Coordenação de Aperfeiçoamento de Pessoal de Nível Superior - Ministério da Educação).

A seleção dos artigos, das dissertações e das teses aconteceu em janeiro e fevereiro de 2013. O período de referência determinado foi de 2002 a 2012 . Para dissertações e teses foi até 2011 , pela disponibilidade na fonte consultada. Para cada fonte, foi adotado um modo específico de identificação dos textos:

- SciELO Brasil: em "pesquisa de artigos", utilizamos os termos "trabaIho", "educação" e "infantil" e definimos o "resumo" como campo, de modo que essas três palavras sempre estivessem presentes.

- Site da ANPEd: a partir de "reuniões anuais", fomos da 25 (2002) à $35^{a}(2012)$ reunião, nas páginas do "Grupo de Trabalho 07 - Educação de Crianças de $\mathrm{O}$ a 6 anos".

- Banco de Teses da Capes: em "ferramenta de busca e consulta de resumos", utilizamos os termos "trabalho", "educação" e "infantil" e definimos 
o "assunto" como campo, de modo que essas três palavras sempre estivessem presentes.

A escolha dos termos "trabalho", "educação" e "infantil" se deve ao uso corrente dessas palavras na literatura especializada em educação. A capacidade de abrangência desses termos, aliada à precisão que carregam no sentido de sempre estarem presentes em discussões sobre "o trabalho na educação infantil", foi o nosso principal critério de seleção. Dessa forma, diminuindo a restrição, uma quantidade enorme de textos foi identificada, o que fez com que, provavelmente, todos os trabalhos que tratam do tema fossem contemplados na primeira etapa da pesquisa.

Em seguida, passamos para a leitura dos títulos, das palavras-chave e dos resumos. A partir do grau de tratamento dado pelo resumo, avaliamos a afinidade do trabalho com o nosso tema de interesse.

Posteriormente, dentre todos os trabalhos, selecionamos os que tratam especificamente do tema, nas perspectivas da profissão docente na educação infantil e da saúde e qualidade de vida no trabalho: dois artigos do periódico Educar em Revista - um do Cadernos de Pesquisa e um da Revista Brasileira de Educação; três trabalhos apresentados em reuniões anuais da ANPEd; vinte dissertações e quatro teses. A seguir, o Quadro 1 apresenta os trabalhos selecionados por tipo, ano, área e instituição:

\section{Quadro 1}

Artigos, dissertações e teses selecionados a partir da leitura e avaliação dos resumos, conforme o tema: as condições do trabalho docente na educação infantil no Brasil

\begin{tabular}{llll}
\hline Tipo & Ano & Área & Instituição \\
Artigo SciElO & 2010 & Educação & UNIR \\
& 2010 & Educação & UFMG, UFPR \\
& 2011 & Educação & USP \\
& 2012 & Educação & UFMG \\
Artigo ANPEd & 2006 & Educação & UFG \\
& 2007 & Educação & Unilese-MG \\
& 2008 & Educação & Unicamp-UFES
\end{tabular}




\begin{tabular}{|c|c|c|c|}
\hline \multirow[t]{20}{*}{ Dissertação } & 2003 & Psicologia & UCDB \\
\hline & 2004 & Educação & UFPel \\
\hline & 2005 & Psicologia & UNESP \\
\hline & 2005 & Educação & UNIVALI \\
\hline & 2006 & Educação & UFG \\
\hline & 2006 & Educação Domestica & UFV \\
\hline & 2006 & Saúde & USP \\
\hline & 2007 & Educação & PUC-MG \\
\hline & 2009 & Educação & UNESP \\
\hline & 2009 & Administração de Empresas & UECE \\
\hline & 2009 & Educação & UFMG \\
\hline & 2010 & Educação & PUC-SP \\
\hline & 2010 & Educação & UFPA \\
\hline & 2010 & Educação & UFSC \\
\hline & 2010 & Psicologia & UnB \\
\hline & 2010 & Educação & UFSC \\
\hline & 2011 & Educação & PUC-RS \\
\hline & 2011 & Educação & UFSC \\
\hline & 2011 & Educação & UFSRG \\
\hline & 2011 & Enfermagem & UFSC \\
\hline \multirow[t]{4}{*}{ Tese } & 2006 & Psicologia & USP \\
\hline & 2007 & Educação & UFSRG \\
\hline & 2011 & Educação & UFRN \\
\hline & 2011 & Educação & PUC-SP \\
\hline
\end{tabular}

Fontes | Portal SciELO | Portal da ANPEd| Banco de Teses da Capes

Pode-se perceber que se trata de um assunto de interesse recente para mestrandas/os, doutorandas/os e pesquisadoras/es em geral. Desses trinta e um trabalhos, que compreendem os últimos dez anos, dezoito foram publicados ou defendidos entre 2009 e 2012 . A grande maioria das teses/ dissertações corresponde a linhas de pesquisa situadas na área da educação. Vinte e quatro são de pesquisadoras/es de universidades públicas e sete de instituições privadas, sendo que nenhuma concentra uma quantidade significativa 
de trabalhos, ou seja, o tema ainda não é uma referência consolidada como objeto de atenção e interesse.

No Quadro 2, evidencia-se um conjunto variado de regiões e municípios contemplados nos textos selecionados.

\section{Quadro 2}

Municípios pesquisados nos textos selecionados

\begin{tabular}{llll}
\hline Região & Estado & Município & Ano de Publicação \\
Norte & RO & Rolim de Moura & 2010 \\
& RO & Alta Floresta D'Oeste & 2010 \\
& RO & Nova Brasilândia D'Oeste & 2010 \\
& PA & Oriximiná & 2010 \\
& PA & Óbidos & 2010 \\
Nordeste & CE & Fortaleza & 2009 \\
& PB & Campina Grande & 2011 \\
Centro-Oeste & GO & Goiânia & 2006,2006 \\
& MS & Campo Grande & 2011 \\
& SP & Assis & 2005 \\
& MG & Viçosa & 2006 \\
& SP & Ribeirão Preto & 2006 \\
& MG & Belo Horizonte & $2007,2009,2010,2012$ \\
& SP & Araraquara & 2009 \\
& MG & Unaí & 2010 \\
SP & São Paulo & 2010 \\
& MG & Uberaba & 2011 \\
RS & Pelotas & 2004 \\
SC & Balneário Camboriú & 2005 \\
RS & Porto Alegre & 2007,2011 \\
SC & Florianópolis & 2010,2011 \\
SC & São José & 2011
\end{tabular}


RS Cidreira 2011

PR Curitiba 2011

Fontes | Portal SciELO; Portal da ANPEd, Banco de Teses da Capes

Os resultados foram agrupados nos seguintes assuntos que julgamos expressar parte dos componentes das condições de trabalho docente: identidade/aspectos subjetivos, políticas públicas educacionais, condições profissionais e saúde/bem-estar.

A maioria dos trabalhos aqui analisados são estudos de caso, localizados em determinados municípios, restritos a certas unidades educacionais ou a um pequeno grupo de sujeitos de pesquisa.

\section{Identidade}

Um ponto de partida sobre a questão da identidade é o trabalho de Fernandes (2010), baseado em levantamento de dissertações de mestrado junto ao Banco de Teses da Capes, período de 1996-2009. A análise de conteúdo das treze dissertações selecionadas ressaltou as seguintes concepções de docência: a) maternagem e cuidado; b) ensino e preparação para as etapas seguintes da educação básica; c) educação e cuidado indissociáveis; e d) multiplicidade de funções que ultrapassam a relação educacional com a criança. Foi observada a presença de concepção que prioriza o ensino/ aprendizagem, o que pode significar uma forma de aproximação do status superior em que as/os professoras/es do ensino fundamental são colocadas/ os.

Soares (2011) reflete sobre os esquemas mentais estruturantes de um possível habitus professoral entre docentes da educação infantil nas redes públicas estadual e municipal de Campina Grande - PB. Foi observada a existência de uma única representação social entre as 308 professoras pesquisadas, estruturada pela confluência entre um habitus religioso lem que se analisou o gosto literário e musical) e um habitus maternal, relevando-se valores como o compromisso, o amor, a dedicação, a paciência, a responsabilidade e o gratificante. Verificou-se também a ambiguidade entre a docência e a maternagem. 
Cota $(2007 a ; 2007 b)$ discute o fato de trabalhadoras de creche, conhecidas como crecheiras, recreadoras, monitoras e assistentes, não se perceberem como professoras de educação infantil. Cinco trabalhadoras de distintas creches, situadas em três municípios da região metropolitana de Ipatinga-MG, participaram da pesquisa, que usou a História Oral. Quatro traços identitários foram observados: a atitude ambígua entre maternagem e a profissionalidade, a origem socioeconômica caracterizada pela baixa renda, a formação escolar básica precária e o sentimento de pertencimento a um universo da creche fora da educação infantil.

A pesquisa de Diamente (2010) também detectou percepção da desvalorização social da docência na educação infantil, entre professoras de unidades educacionais situadas em contextos sociais diversos.

Em sentido próximo, Venzke (2004) constatou dois fatores fundamentais exercendo influência sobre a constituição das identidades docentes de professoras da educação infantil da rede pública municipal de Pelotas-Rio Grande do Sul: as condições de trabalho, entendidas como a estrutura física da instituição, os recursos materiais, o regime de trabalho, o salário, a multiplicidade de funções e os discursos presentes na sociedade a respeito da docência na educação infantil. Os sentimentos de desvalorização observados estão na origem do desconforto, da insatisfação e da vontade de abandonar a primeira etapa da educação básica para atuar no ensino fundamental, manifestados pelas pesquisadas.

Hugo da Silva (2006) indaga sobre a identidade política das mulheres que trabalham com crianças pequenas na rede pública municipal de Goiânia, considerando um contexto caracterizado pela crise estrutural do capital, pela predominância das políticas neoliberais e pelo aumento das exigências sobre a classe trabalhadora. Concluiu que:

[...] a) as instituições de educação infantil são constituídas sob as determinações ideológicas e históricas do conflito entre capital e trabalho; b) o trabalho na educação infantil é mediado por aspectos ideológicos e práticos de natureza assistencialista; c) a feminização/sexualização do trabalho docente na educação infantil reitera a divisão entre produção e reprodução; d) não existe um diálogo entre sindicato docente e trabalhadoras da educação infantil. (SIIVA, 2006, p. 8). 


\section{Políticas públicas educacionais}

Otrabalho docente na educação infantil nas políticas educacionais aparece constantemente caracterizado pela sua situação de desvalorização.

Dois estudos, o de Alves e Pinto (201 1 ) e o de Siller e Côco (2008), apresentaram informações mais abrangentes sobre os/as docentes da educação infantil. O primeiro, ao tratar da remuneração e características do trabalho docente no Brasil, mostra que, em comparação com as outras etapas da educação básica, as quais também apresentam rendimentos abaixo do esperado para certo nível de formação em relação a outras ocupações, sempre a educação infantil está situada na posição de maior desvalorização salarial.

○ segundo abrange o estado do Espírito Santo, elegendo o estudo de editais de concursos públicos, que podem ser considerados como uma das principais fontes de informação acessíveis sobre a realidade empregatícia dos sujeitos docentes da educação infantil pública brasileira. Apesar da variedade de denominações verificadas, um cargo geral de "professor" pode ser identificado nos 42 editais analisados. A formação docente mínima exigida, em conformidade com o art. 62 da Lei de Diretrizes e Bases da Educação

140 Nacional, Lei n. 9394/12/1996, e com o art. 04 da Resolução 03/1997 do Conselho Nacional de Educação, aparecia nos editais. No entanto, na maioria dos mesmos, foi observado que a formação superior em curso de licenciatura plena em pedagogia é valorizada como preferencial, tanto na avaliação de títulos na seleção, quanto na remuneração. Outra informação importante diz respeito à remuneração. Foi constatado que prevalece a política salarial docente referenciada na etapa e modalidade de ensino e não na formação alcançada (título ou habilitação), como preconiza a LDB no inciso IV do art. 67.

Quando está em questão a creche, aparece a categoria de "profissional de apoio", que recebe tratamento desigual. Com uma variedade de denominações, esse cargo é menos exigente quanto à formação, como nos casos em que se requer apenas o ensino fundamental incompleto. Soma-se a esse ponto, em comparação com a categoria de "professor", a carga horária de trabalho maior, a remuneração menor e o não enquadramento na carreira do magistério público, mesmo quando tem formação requerida. (SILLER; CÔCO, 2008). 
Vieira e Souza (2010) estudaram a situação de trabalho e emprego na educação infantil em Belo Horizonte, capital de Minas Gerais, em estabelecimentos de ensino público (estadual e municipal) e de ensino privados; efetuaram levantamento de fontes documentais, da legislação, estatísticas; realizaram entrevistas e observações, no intuito de evidenciar as relações entre as tipologias das instituições de educação infantil e as formas de contratação, carreira, salário e condições de trabalho. Os estabelecimentos estudados foram escolhidos, segundo amostra intencional, por localização e público preferencial atendido. $\bigcirc$ estudo evidenciou a existência de profissionais com status e formação/qualifica-ção diferenciados, bem como a presença de variadas modalidades de relações de emprego e trabalho que, segundo as autoras, revelam processo de precarização no exercício profissional na educação infantil. Segmentações no interior do setor público, e entre setor público e privado, reiteram desigualdades históricas observadas entre as etapas da educação básica, na qual a educação infantil tem lugar subalterno. Por outro lado, uma demanda crescente por reconhecimento profissional foi constatada.

Silva (2010) avalia os efeitos do Fundo de Manutenção e Desenvolvimento da Educação Básica e Valorização dos Profissionais da Educação - Fundeb e da Lei do Piso Salarial Nacional na política de remuneração das/es professoras/es das redes públicas municipais de ensino de Óbidos e Oriximiná no Pará. Foi constatado que, após dois anos de vigência do fundo e das novas referências salariais, não houve modificação na política remuneratória dos sujeitos docentes da educação infantil e do ensino fundamental nos dois municípios.

Por sua vez, Custódio (2011) pesquisa a relação entre as políticas educacionais de valorização do magistério e os processos de profissionalização dos sujeitos docentes da educação infantil e dos anos iniciais do ensino fundamental da rede pública municipal de Uberaba - Minas Gerais. Constata que o magistério, nessas duas etapas, não tem o reconhecimento merecido em relação à formação profissional e carreira. $\bigcirc$ discurso de valorização e profissionalização procura dar legitimidade às políticas que, por serem insatisfatórias, contribuem para a existência de "práticas desprofissionalizantes." (CUSTÓDIO, 201 1, p. 7).

Também pouco estudado é o assunto trabalhado por Martins (201 1), que trata dos profissionais de apoio em turmas de educação infantil e de ensino fundamental das redes públicas municipais da Regional Grande Florianópolis, 
particularmente Florianópolis e São José - Santa Catarina, que possuem crianças da educação especial. Foram definidos como tópicos de referência: a presença desse profissional, as suas atribuições previstas e realizadas e as suas condições de trabalho. O principal problema verificado é o fato de esse cargo ser desvalorizado, apesar de ser um dos pilares da política de inclusão que vem sendo desenvolvida no local. Destacou, na situação estudada, a ausência de formação, a insuficiente regulamentação do cargo, a remuneração baixa, a sobrecarga de trabalho e as condições inadequadas de atuação.

\section{Condições profissionais, saúde e bem-estar}

Purin (201 1) analisa o trabalho docente na educação infantil e no ensino fundamental na rede de ensino de Cidreira-Rio Grande do Sul, considerando o processo de reestruturação produtiva do capital e as mudanças no mundo do trabalho daí advindas, que repercutem diretamente nas relações de trabalho na escola pública, gerando intensificação, precarização e adoecimento. Observou formas de resistência dos sujeitos docentes, como o empenho no fazer crítico com as crianças e a organização sindical.

Alexandre (2006) analisa o espaço de trabalho dos sujeitos docentes da educação infantil do Laboratório de Desenvolvimento Infantil da Universidade Federal de Viçosa-Minas Gerais, numa perspectiva ergonômica. Tendo como referência o conforto, o bem-estar, a saúde e a segurança, foi verificado que as educadoras adotam posturas inadequadas na realização das atividades, levando em consideração o tempo de permanência da criança, a frequência de comportamentos e a execução do trabalho, o que exige uma intervenção ergonômica. Essas atitudes são produzidas e agravadas pelas condições consideradas inadequadas de trabalho.

Pinto (2009) e Pinto, Duarte e Vieira (2012) desenvolveram um estudo sobre as condições de trabalho das educadoras infantis nas Unidades Municipais de Educação Infantil - UMEls e nas escolas municipais de Belo Horizonte. Foi constatado que a criação das UMEls e a expansão das matrículas municipais nessa etapa da educação básica se baseou na criação de um cargo docente inferior ao de professor. Chamada de "educador infantil", essa categoria possui uma remuneração menor quando comparada com a referente 
às demais etapas. Observa-se também a atribuição de novas tarefas, o que traz implicações como precarização e intensificação do trabalho docente.

Um tema ainda pouco explorado é o que nos apresenta Graziela Conceição (2010), abordando a situação de trabalho das auxiliares de sala da educação infantil da rede pública municipal de Florianópolis - Santa Catarina. Constatou que, apesar de $98 \%$ das 975 pesquisadas terem formação superior e de exercerem atividade de docência, elas não estão vinculadas ao Quadro do Magistério, mas sim ao Quadro da Carreira Civil. Isso tem implicações negativas sobre a carreira e a remuneração, principalmente em comparação com o cargo de professor. Observou que a incidência dos processos de precarização e intensificação do trabalho docente é mais severa sobre as auxiliares. No entanto, no contexto em questão, o envolvimento e a participação sindical vêm sendo uma estratégia de resistência importante, que já teve como resultado a garantia do direito à formação docente inicial e continuada.

Com resultados um pouco diferentes dos demais, Alvarenga (2009) apresenta as condições profissionais em que se encontram as professoras de pré-escolas da rede municipal pública de Araraquara - São Paulo. Trata-se de um contexto de exceção, tendo em vista as regras de contratação e a carreira docente vigente, sendo garantida a exigência de formação profissional superior, a realização periódica de concursos, os direitos trabalhistas e previdenciários e um "plano de carreiras, cargos e vencimentos" que determina um status e remuneração equivalentes aos demais professores dos anos iniciais do ensino fundamental, incluindo progressão funcional e formação continuada. No entanto, a atribuição de carga suplementar de trabalho e as mudanças na aposentadoria sugerem indícios de precarização, enquanto a necessidade da dupla jornada de trabalho, devido a dificuldades financeiras, e a implantação do "prêmio assiduidade", somado ao aumento das exigências, indicam processos de intensificação laboral.

Também temos as informações produzidas por Bigaton (2005), que analisou as diferentes esferas - social, econômica e cultural - que constituem os perfis de professoras/es da educação infantil e do ensino fundamental da rede pública municipal de Balneário Camboriú - Santa Catarina. Ela pesquisou 442 professoras/es de quinze instituições educacionais. Partiu da hipótese de que os perfis são indicadores não só das escolhas profissionais, mas também da ação pedagógica. Foi verificado que a maioria dos sujeitos de pesquisa 
está satisfeita com o ambiente físico da unidade educacional, não tem motivos para mudar de profissão e se encontra numa situação pessoal favorável ao trabalho docente.

Na perspectiva da saúde, Defina lqueda (2006) realiza uma investigação sobre a qualidade vocal de professoras/es da educação básica - educação infantil, ensino fundamental e ensino médio - da rede pública municipal de Ribeirão Preto - São Paulo, com o propósito de conhecer a influência das alterações de voz, produzidas na atividade laboral, sobre aspectos de ordem pessoal e profissional. Além do uso excessivo e intenso da voz, podem-se incluir como fatores desencadeantes de um distúrbio: a higiene do ambiente educacional, o número de educandas/os e a condição acústica do ambiente, além do estresse de motivação diversa, como a remuneração muito insatisfatória e as demais condições inadequadas de trabalho. Foi verificado que $93 \%$ dos sujeitos de pesquisa queixaram do problema de disfonia. No entanto, a autora mostrou que poucos percebem a gravidade dessa doença ocupacional e os seus efeitos nas relações sociais, o que leva à conclusão de que é baixa a percepção da influência dos problemas vocais gerados no trabalho sobre a qualidade de vida.

144 Detendo-se em outro assunto, Bertão (2005) promove uma discussão sobre o conflito entre o desejo e o sofrimento existente nas relações e atividades profissionais. Ao analisar a trajetória de vida do sujeito docente da educação infantil e os processos de escolha da profissão, foi possível identificar o modo como angústias e desejos formados na infância são reeditados na vivência laboral adulta e compreender o sofrimento psíquico que constitui a docência. Para tanto, foi utilizado o método psicanalítico. Cinco professoras da educação infantil foram entrevistadas e revelaram questões sobre as suas relações pessoais e profissionais. Foi observado que, em um contexto de trabalho no qual a fala não é valorizada, a busca atual por sentidos e significados formulados em experiências emocionais na infância dificulta a transformação do sofrimento patológico em criativo.

Rosi (2003) procura identificar os níveis e as fontes de estresse ocupacional em 62 educadoras que trabalham com crianças de zero a seis anos, em unidades empresarial, filantrópica, particular e pública, da cidade de Campo Grande-Mato Grosso do Sul. Tendo traçado um perfil das educadoras, foram verificadas as avaliações sobre a própria atividade profissional, as fontes de estresse do trabalho, as avaliações sobre a incidência do estresse, os tipos de 
sintomas e as fontes externas de estresse dos últimos doze meses. A alta incidência de estresse observada, manifestada em sintomas físicos e em exaustão, não se diferencia entre as instituições. Curiosamente, o destaque dado ao salário insatisfatório e à instabilidade no emprego como fontes de estresse, em geral, não foi suficiente para que as pesquisadas avaliassem o trabalho como estressante.

Beraldo (2006) também se dedica a demonstrar como essas educadoras lidam com o estresse ocupacional. As fontes de satisfação encontradas são as oportunidades, os desafios e as recompensas inerentes à profissão e às relações interpessoais, em especial com as crianças. Já as fontes de insatisfação são as experiências de desrespeito e desconsideração vividas com as/os responsáveis pelas crianças, enquanto as fontes de stress são as tensões entre as colegas de trabalho, as suspeitas e acusações dos/as responsáveis pelas crianças e as dificuldades de relacionamento e de aprendizagem das crianças. Uma estratégia de coping - de enfrentamento do desconforto - verificada é o riso. Apesar da percepção de desvalorização, "[... ] as educadoras encontram motivos de satisfação; estão investindo em sua formação continuada e pretendem, na maioria dos casos, continuar a atuar em educação infantil ou em outras áreas educacionais." (BERALDO, 2006, p. 6). Outros fatores colocados hipoteticamente como desencadeadores de stress não foram confirmados a partir da visão das educadoras, como, por exemplo, as ambiguidades do papel docente na educação infantil, a sobrecarga de exigências e a incidência de restrição da autonomia.

Aranda (2007) trata também da questão do mal-estar docente entre as/os professoras/es das redes municipal, estadual e particular de Porto Alegre - Rio Grande do Sul. A definição de mal-estar docente é a dificuldade de lidar com as problemáticas que estão presentes na unidade educacional e se manifesta em angústia, desconforto e sentimento de impotência. Através da análise das percepções expressas pelos sujeitos de pesquisa, os principais fatores de mal-estar estão nas relações com as crianças, com a comunidade escolar, com as/os colegas de trabalho e com a equipe diretiva. Podem-se destacar também as dificuldades em lidar com as crianças, sujeitos da política de inclusão.

Branquinho (2010) também discute os efeitos das condições de trabatho docente sobre a percepção de bem/mal-estar, mas através da abordagem da "ergonomia da atividade aplicada à qualidade de vida no trabalho". 
Participaram da pesquisa 472 professoras/es da educação infantil e do ensino fundamental da rede pública municipal de Unaí - Minas Gerais. Conforme as opiniões dos sujeitos de pesquisa, três fatores, fundamentalmente, constituem o que significa "qualidade de vida no trabalho": a) relações profissionais harmoniosas e cooperativas; b) valorização profissional; e c) condições ótimas de trabalho. Cerca de 75\% disseram apresentar bem-estar no trabalho. Os aspectos críticos mais apontados foram a "organização do trabalho" e as "condições de trabalho". Mostrou-se também que as principais fontes de bem-estar são: a percepção da importância social do trabalho docente e as relações socioprofissionais. Já as mais importantes fontes de mal-estar indicadas são: a indisciplina das crianças, a negligência dos/as responsáveis pelas crianças, as cobranças de toda ordem e a desvalorização profissional.

Dohms (201 1) analisa as influências que o mal/bem-estar docente exercem sobre a docência na educação básica em uma escola tradicional de Porto Alegre - Rio Grande do Sul. As respostas dos 25 questionários aplicados e a análise de conteúdo das entrevistas com as/os docentes evidenciam os seguintes fatores como fontes de geração de estresse: a) inexistente ou precária relação com a família das crianças/jovens; b) falta de recursos materiais; c) 146 indisciplina das/os estudantes; d) grande quantidade de exigências burocráticas; e) trabalho além da jornada atribuída ao cargo; f) desvalorização salarial; g) avaliações sistemáticas direcionadas aos estudantes; h) imagem desvalorizada da docência; e i) dificuldade no atendimento das crianças/jovens com necessidades educacionais especiais. Por outro lado, as estratégias de diminuição do mal-estar incluem: a) relações positivas com as crianças/jovens; b) apoio de colegas de trabalho e do sindicato; c) reflexão sobre o papel docente; d) aproveitamento das férias escolares; el planejamento antecipado das atividades docentes; f) administração sistemática do tempo; gl dedicação a hobby e passatempos; e h) apoio familiar e de amigos. Ressalta a existência de elevado nível de estresse entre os pesquisados e a tendência observada de níveis positivos da autoimagem e da autoestima.

Na perspectiva da administração, Neff (2009) realizou uma pesquisa numa empresa de educação infantil, com o propósito de investigar a questão da Qualidade de Vida no Trabalho (QVT). O autor não informou o município. Participaram como sujeitos 83 funcionárias/os, entre elas/es, educadoras/ es, auxiliares, berçaristas e pessoas em cargos de nível operacional e coordenação. No geral, verificou-se uma grande satisfação em relação às oito 
dimensões da QVT, apesar das dimensões "compensação justa e adequada" e "oportunidade de crescimento e segurança" apontarem sinais de total insatisfação. A conclusão é a de que a natureza do trabalho pode ser considerada um dos aspectos mais importantes na constituição da percepção satisfatória sobre a QVT, em comparação com fatores extrínsecos ao trabalho, como é o caso do salário.

Giovannetti (2011) identifica e analisa os fatores que têm efeitos sobre a saúde emocional/mental de sujeitos docentes da educação infantil da rede pública municipal de Curitiba - Paraná. Integrando história de vida com história de trabalho, foi possível identificar os principais elementos desencadeadores de sofrimento/adoecimento: a desvalorização do trabalho docente, os conflitos nas relações interpessoais e a desgastante organização do trabalho, que inclui o elevado tempo de exercício na função, o grande número de crianças por turma, o tamanho reduzido das salas, os ruídos e a sobrecarga de trabalho. Por outro lado, pode-se dizer que contribuem com a saúde emocional/mental dos sujeitos docentes: a relação afetiva com as crianças, a percepção da importância da docência para o desenvolvimento das crianças, o reconhecimento do trabalho pela coordenação, supervisão, direção, pelas próprias crianças e famílias. No entanto, os fatores negativos têm um peso maior sobre os positivos e, inclusive, impedem que estes se manifestem. Nesse contexto desfavorável, restam o tratamento psicológico/médico especializado e o afastamento da função como alternativas de recuperação, além da resistência a voltar a exercer as atividades profissionais sob as mesmas condições inadequadas.

\section{Considerações finais}

Este levantamento bibliográfico significa uma incursão inicial para sistematizar pesquisas sobre condições de trabalho na educação infantil. $\bigcirc$ aprofundamento do tema requer a pesquisa em periódicos de áreas diversas em diferentes bases e igualmente o esclarecimento dos sentidos divergentes sobre condições de trabalho observados nos textos; diferentes sentidos e diferentes abordagens que exijam maiores esforços de sistematização. 
Observamos que o eixo que perpassa o conjunto de estudos é a desvalorização social da atividade profissional de cuidar-educar crianças pequenas em instituições educacionais.

A predominância das mulheres no exercício da docência na educação infantil é indicada como um dos fatores determinantes para a desvalorização e a naturalização do trabalho na área, bem como para associar maternagem e docência. (ALVES, 2006).

Dois processos nas condições de trabalho docente estão, em menor ou maior grau, presentes em todos os estudos analisados: a precarização e a intensificação. Em síntese, o primeiro se refere à atribuição de novas funções e tarefas ao mesmo tempo em que não são fornecidas as condições necessárias para o seu cumprimento. Pode também ser entendido como o emprego de pessoas sem a formação requerida pela legislação educacional, ocupando postos de trabalho criados para substituir professore/as no exercício do trabaIho pedagógico. Já o segundo trata da imposição de sobrecarga, seja através da necessidade de realização de atividades extras fora da jornada oficial de trabalho ou mesmo através da baixa remuneração, que exige a complementação salarial por meio do compromisso com outros cargos.

Alguns elementos comuns foram identificados nos estudos: a) baixa remuneração; b) sobrecarga de trabalho; c) precário ou inexistente "plano de cargos, carreiras e salários" pertencente ao magistério; d) falta de seleção por concursos públicos; el ambiguidades nas exigências quanto à formação para o exercício do magistério na educação infantil; f) não garantia de formação pública inicial e continuada; gl produção e reprodução de cargos de situação precária, como o de auxiliar e equivalentes para atuar principalmente nas creches; h) infraestrutura inadequada da unidade educacional; i) recursos materiais e pedagógicos precários ou inexistentes; i) número elevado de crianças por turma e k) inexistência de apoio educacional especializado no atendimento à inclusão.

Somadas a esses fatores, temos as seguintes atribuições das professoras ou auxiliares, além do trabalho nas classes e berçários com as crianças: a) elaboração e planejamento de atividades; b) avaliação e registro avaliativo das crianças; c) elaboração e implementação do projeto político pedagógico; d) planejamento e participação na gestão da unidade educacional; e) elaboração e realização de projetos coletivos; f) elaboração e realização de projetos 
de participação comunitária; f) substituição de funcionários em funções diversas; g) participação em cursos de formação continuada fora da jornada oficial de trabalho; h) realização de "atividades extraclasse" não remuneradas; e il prática da política de inclusão de crianças com deficiência ou em situação de vulnerabilidade social, sem formação adequada e apoio especializado.

A análise das condições de trabalho e de vida de mulheres-professoras/auxiliares numa perspectiva de gênero, tal como empreendida por Zibetti e Pereira (2010), indica tensões geradas pela desigual divisão das atribuições domésticas e pela ausência de serviços públicos de atendimento às mães trabalhadoras, inclusive as que exercem a docência. Como mostram as autoras acima citadas, em estudo realizado com professoras de educação infantil e séries iniciais de ensino fundamental de três redes municipais de Rondônia, as jornadas duplas - trabalho doméstico e trabalho docente - e até triplas - trabalho doméstico, trabalho docente e formação docente/atividades extraclasse - , em condições precárias e sob processos de intensificação das exigências, mais a educação das/os filhas/os e a desvalorização de toda ordem são situações que moldam em geral a vida dessas mulheres. Analisa-se que disso decorrem os sintomas de estresse, o sentimento de mal-estar, as doenças de efeitos físicos e mentais e a insatisfação no trabalho.

Os sentimentos de afeto pelas crianças e os sentimentos positivos que as crianças nutrem pelas suas professoras na educação infantil são elementos gratificantes reiteradamente citados pelas pesquisadas, nos estudos aqui trazidos, para permanecer e buscar melhores condições de trabalho nas instituições educacionais.

Tais questões nos instigam a novas pesquisas que articulem os aportes da sociologia das profissões, dos estudos de gênero e trabalho docente.

\section{Referências}

ALEXANDRE, Adla Alves. Análise das condições de trabalho dos educadores de criança numa perspectiva ergonômica: o caso do laboratório de desenvolvimento infantil. 2006. 130f. Dissertação (Mestrado em Economia Doméstica) - Programa de Pós-Graduação em Economia Doméstica, Universidade Federal de Viçosa, Viçosa, 2006.

ALVARENGA, Vanessa Cristina. A profissionalização do trabalho docente: um estudo das condições de trabalho de professoras de pré-escola. 2009. 169f. Dissertação Mestrado 
em Educação) - Programa de Pós-Graduação em Educação, Universidade Estadual Paulista "Júlio de Mesquita Filho", Araraquara, 2009.

ALVES, Thiago; PINTO, José Marcelino de Rezende. Remuneração e características do tra-balho docente no Brasil: um aporte. Cadernos de Pesquisa, São Paulo, v. 143, n. 41 , p. 606-639, maio/ago. 2011.

ALVES, Nancy Nonato de Lima. "Amor à profissão, dedicação e o resto se aprende": significados da docência em educação infantil na ambiguidade entre a vocação e a profissionalização. In: REUNIÃO ANUAL DA ANPEd, 29., 2006, Caxambu. Anais... Caxambu: ANPEd: 2006. Disponível em: <http//:www.anped.org.br> Acesso em: 15 fev. 2013.

ARANDA, Silvana Maria. Um olhar implicado sobre o mal-estar docente. 2007. 149f. Tese (Doutorado em Educação) - Programa de Pós-Graduação em Educação, Universidade Federal do Rio Grande do Sul, Porto Alegre, 2007.

BARBOSA, Ivone; ALVES, Nancy; MARTINS, Telma; MAGALHÃES, Solange. Políticas públicas para a educação infantil em Goiânia: a luta por um projeto político-social. In: REUNIÃO ANUAL DA ANPEd, 28., 2005, Caxambu. Anais... Caxambu: ANPEd, 2005. Disponível em: <http//:www.anped.org.br> Acesso em: 15 fev. 2013.

BERALDO, Katharina Elisabeth Arnold. Educadoras de creche: percepção de motivos de satisfação, de insatisfação e de estresse vinculados ao desempenho profissional. 2006. $200 f$. Tese. (Doutorado em Psicologia) - Programa de Pós-Graduação em Psicologia, Universidade de São Paulo, São Paulo, 2006.

BERTÃO, Flávia Renata Bertonha Manoel. Desejo de ser professor de educação infantil: contribuições para estudo da constituição do sujeito no trabalho. 2005. 120f. Dissertação (Mestrado em Psicologia) - Programa de Pós-Graduação em Psicologia, Universidade Estadual Paulista "Júlio de Mesquita Filho", Assis, 2005.

BIGATON, Roslei Aparecida Sinderski. Perfil de professores da educação básica e análise multidimensional. 2005. 16 lf. Dissertação (Mestrado em Educação) - Programa de PósGraduação em Educação, Universidade do Vale do Itajaí, Balneário Camboriú, 2005.

BRANQUINHO, Neuzani das Graças Soares. Qualidade de vida no trabalho e vivências de bem-estar e mal-estar em professores da rede pública municipal de Unaí/MG. 2010. $117 f$. Dissertação (Mestrado em Psicologia) - Programa de Pós-Graduação em Psicologia, Universidade de Brasília, Brasília, 2010.

BRASIL. Lei n. 9.394, de 20 de dezembro de 1996. Estabelece as diretrizes e bases da Educação Nacional. Diário Oficial [da] União, Brasília, DF, 23 dez. 1996 
CHÁVEZ, Rodrigo; GARRIDO, Manuel. Condições psicossociais do trabalho. In: OLIVEIRA, Dalila; DUARTE, Adriana; VIEIRA, Lívia. Dicionário: trabalho, profissão e condição docente. Belo Horizonte: FaE/UFMG, 2010. 1 CD-ROM.

CONCEIÇÃO, Graziela Pereira da. Trabalho docente na educação infantil pública de

Florianópolis: um estudo sobre as auxiliares de sala. 2010. 140f. Dissertação (Mestrado em Educação) - Programa de Pós-Graduação em Educação, Universidade Federal de Santa Catarina, Florianópolis, 2010.

COTA, Tereza Cristina Monteiro. "A gente é muita coisa para uma pessoa só": desvendando identidades de "professoras" de creches. 2007. 122f. Dissertação (Mestrado em Educação) - Programa de Pós-Graduação em Educação, Pontifícia Universidade Católica de Minas Gerais, Belo Horizonte, 2007a.

COTA, Tereza Cristina Monteiro. "A gente é muita coisa para uma pessoa só": desvendando identidades de "professoras" de creches. In: REUNIÃO ANUAL DA ANPEd, 30., Anais... Caxambu: ANPEd, 2007b. Disponível em: <http//:www.anped.org.br> Acesso em: 15 fev. 2013.

CUSTÓDIO, Maria do Carmo. Profissionalização do magistério na educação básica: análise da valorização profissional do professor da educação infantil e anos iniciais do ensino fundamental. 2011 1. 284f. Tese (Doutorado em Educação) - Programa de Pós-Graduação em São Paulo: Pontifícia Universidade Católica de São Paulo, Educação, 2011.

DIAMENTE, Juliana. A dimensão subjetiva do trabalho em educação infantil: $\bigcirc$ impacto da desvalorização nos sentidos constituídos pelos professores. 2010. 175f. Dissertação (Mestrado em Educação) - Programa de Pós-Graduação em Educação, Pontifícia Universidade Católica de São Paulo, São Paulo, 2010.

DOHMS, Karina Pacheco. Níveis de mal/bem-estar docente, de autoimagem e autoestima e de autorrealização de docentes em uma escola tradicional de Porto Alegre. 2011. $112 f$. Dissertação (Mestrado em Educação) - Programa de Pós-Graduação em Educação, Universidade Católica do Rio Grande do Sul, Porto Alegre, 2011.

FERNANDES, Tatiane Márcia. Professoras de educação infantil: dilemas da constituição de uma especificidade profissional. Um estudo sobre a produção científica brasileira (19962009). 2010. 106f. Dissertação (Mestrado em Educação) - Programa de Pós-Graduação em Educação, Universidade Federal de Santa Catarina, Florianópolis, 2010. 
GIOVANNETTI, Mônica de Oliveira. Saúde mental e trabalho no contexto da educação infantil. 2011 . 171f. Dissertação (Mestrado em Enfermagem) - Programa de Pós-Graduação em Enfermagem, Universidade Federal de Santa Catarina, Florianópolis, 2011.

IQUEDA, Adriana Pereira Defina. Auto-percepção da voz e interferências de problemas vocais: um estudo com professores da rede municipal de Ribeirão Preto/SP. 2006. $165 f$. Dissertação (Mestrado em Saúde) - Programa de Pós-Graduação em Saúde, Universidade de São Paulo, Ribeirão Preto, 2006.

MARTINS, Silvia Maria. O profissional de apoio na rede regular de ensino: a precarização do trabalho com os alunos da educação especial. 2011. 168f. Dissertação. (Mestrado em Educação) - Programa de Pós-Graduação em Educação, Universidade Federal de Santa Catarina, Florianópolis, 2011.

NEFF, Luziane Maria Ribeiro. Aspectos das relações de trabalho que interferem na qualidade de vida do trabalhador. 2009. 128f. Dissertação (Mestrado em Administração de Empresas) - Programa de Pós-Graduação em Administração de Empresas, Universidade Estadual do Ceará, Fortaleza, 2009.

OLIVEIRA, Dalila. Trabalho docente. In: OLIVEIRA, Dalila; DUARTE, Adriana; VIEIRA, Lívia. Dicionário: trabalho, profissão e condição docente. Belo Horizonte: FaE/UFMG, 2010. 1

152 CD-ROM.

OLIVEIRA, Dalila; ASSUNÇÃO, Ada. Condições de trabalho docente. In: OLIVEIRA, Dalila; DUARTE, Adriana; VIEIRA, Lívia. Dicionário: trabalho, profissão e condição docente. Belo Horizonte: FaE/UFMG, 2010. 1 CD-ROM.

OLIVEIRA, Dalila Andrade; VIEIRA, Lívia Fraga. Trabalho docente na educação básica no Brasil. Base de Dados TDEBB/GESTRADO. Belo Horizonte: Faculdade de Educação/ UFMG, 2010. (Apoio SEB/MEC).

PINTO, Mércia Figueiredo Noronha. O trabalho docente na educação infantil pública em Belo Horizonte. 2009. 245f. Dissertação (Mestrado em Educação) - Programa de PósGraduação em Educação, Universidade Federal de Minas Gerais, Belo Horizonte, 2009.

PINTO, Mércia de Figueiredo Noronha; DUARTE, Adriana Maria Cancella Duarte; VIEIRA, Lívia Maria Fraga. O trabalho docente na educação infantil pública em Belo Horizonte. Revista Brasileira de Educação, Rio de Janeiro, v. 17, n. 51, p. 611-626, set./dez. 2012.

PURIN, Paola Cardoso. O trabalho na rede municipal de Cidreira/RS: limites e possibilidades de uma práxis emancipadora. 2011. 69f. Dissertação (Mestrado em Educação) - Programa de Pós-Graduação em Educação, Universidade Federal do Rio Grande do Sul, Porto Alegre, 2011. 
ROSI, Kátia Regina Bazzano da Silva. O "stress" do educador infantil: sintomas e fontes. 2003. 108f. Dissertação (Mestrado em Psicologia) - Programa de Pós-Graduação em Psicologia, Universidade Católica "Dom Bosco", Campo Grande, 2003.

SILLER, Rosali Rauta; CÔCO, Valdete. $\bigcirc$ ingresso de profissionais na educação infantil: - que indicam os editais dos concursos públicos. In: REUNIÃO ANUAL DA ANPEd, 31 ., Caxambu, 2008. Anais... Caxambu: ANPEd, 2008. Disponível em: <http//:www.anped. org.br> Acesso em: 15 fev. 2013.

SILVA, Eldra Carvalho da. A política salarial para os professores da educação básica da rede municipal no contexto do FUNDEB nos municípios de Óbidos e Oriximaná PA. 2010. 190f. Dissertação (Mestrado em Educação) - Programa de Pós-Graduação em Educação, Universidade Federal do Pará, Belém, 2010.

SILVA, Hugo Leonardo Fonseca da. As trabalhadoras da educação infantil e a construção de uma identidade política. 2006. 29 1f. Dissertação (Mestrado em Educação) - Programa de Pós-Graduação em Educação, Universidade Federal de Goiás, Goiânia, 2006.

SOARES, Luisa de Marillac Ramos. Habitus, representações sociais e a construção do ser professora da educação infantil da cidade de Campina Grande - PB. 2011 . $202 f$. Tese (Doutorado em Educação) - Programa de Pós-Graduação em Educação, Universidade Federal do Rio Grande do Norte, Natal, 2011.

TSUDA, Márcia Satomi. Política pública de creche: entre as leis e a realidade. 2008. 139f. Dissertação (Mestrado em Educação) - Programa de Pós-Graduação em Educação, Universidade Estadual Paulista, 2008.

VENZKE, Lourdes Helena Dummer. Professoras das escolas municipais de educação infantil de Pelotas: identidades em construção. 2004. 137f. Dissertação (Mestrado em Educação) - Programa de Pós-Graduação em Educação, Universidade Federal de Pelotas, Pelotas, 2004.

VIEIRA, Lívia Fraga; OLIVEIRA, Dalila Andrade; OLIVEIRA, Tiago Grama; VICTORINO, Thais. Trabalho docente na educação infantil em sete estados brasileiros. TDEBB/GESTRADO. Belo Horizonte: Faculdade de Educação/UFMG, 2013. (Apoio SEB/MEC).

VIEIRA, Lívia Maria Fraga; SOUZA, Gizele de. Trabalho e emprego na educação infantil no Brasil: segmentações e desigualdades. Educar em Revista, Curitiba, n. 1, p. 1 19-139, 2010. (Número especial).

ZIBETTI, Marli Lúcia Tonatto; PEREIRA, Sidnéia Ribeiro. Mulheres e professoras: repercussões da dupla jornada nas condições de vida e no trabalho docente. Educar em Revista, Curitiba, n. 2, p. 259-276, 2010. (Número especial). 
Profa. Dra. Lívia Fraga Vieira Universidade Federal de Minas Gerais Faculdade de Educação Departamento de Administração Escolar Grupo de Estudos sobre Política Educacional e Trabalho Docente | GESTRADO Núcleo de Estudos e Pesquisas sobre Infância e Educação Infantil | NEPEI E-mail | liviafraga@globo.com Tiago Grama de Oliveira
Graduando em Ciências Sociais
Universidade Federal de Minas Gerais
Faculdade de Filosofia e Ciências Humanas
Grupo de Estudos sobre Política Educacional e Trabalho Docente
| GESTRADO
de Estudos e Pesquisas sobre Infância e Educação Infantil | NEPEI
E-mail | ot.grama@gmail.com Tiago Grama de Oliveira
Graduando em Ciências Sociais
Universidade Federal de Minas Gerais
Faculdade de Filosofia e Ciências Humanas
Grupo de Estudos sobre Política Educacional e Trabalho Docente
| GESTRADO
de Estudos e Pesquisas sobre Infância e Educação Infantil | NEPEI
E-mail | ot.grama@gmail.com Tiago Grama de Oliveira
Graduando em Ciências Sociais
Universidade Federal de Minas Gerais
Faculdade de Filosofia e Ciências Humanas
Grupo de Estudos sobre Política Educacional e Trabalho Docente
| GESTRADO
de Estudos e Pesquisas sobre Infância e Educação Infantil | NEPEI
E-mail | ot.grama@gmail.com Tiago Grama de Oliveira
Graduando em Ciências Sociais
Universidade Federal de Minas Gerais
Faculdade de Filosofia e Ciências Humanas
Grupo de Estudos sobre Política Educacional e Trabalho Docente
| GESTRADO
de Estudos e Pesquisas sobre Infância e Educação Infantil | NEPEI
E-mail | ot.grama@gmail.com Tiago Grama de Oliveira
Graduando em Ciências Sociais
Universidade Federal de Minas Gerais
Faculdade de Filosofia e Ciências Humanas
Grupo de Estudos sobre Política Educacional e Trabalho Docente
| GESTRADO
de Estudos e Pesquisas sobre Infância e Educação Infantil | NEPEI
E-mail | ot.grama@gmail.com Tiago Grama de Oliveira
Graduando em Ciências Sociais
Universidade Federal de Minas Gerais
Faculdade de Filosofia e Ciências Humanas
Grupo de Estudos sobre Política Educacional e Trabalho Docente
| GESTRADO
de Estudos e Pesquisas sobre Infância e Educação Infantil | NEPEI
E-mail | ot.grama@gmail.com

Recebido 7 jul. 2013 Aceito 13 out. 2013 